\title{
REVIEW \\ Klotho: a humeral mediator in CSF and plasma that influences longevity and susceptibility to multiple complex disorders, including depression
}

\author{
MG Pavlatou ${ }^{1}$, AT Remaley ${ }^{2}$ and PW Gold ${ }^{1}$
}

Klotho is a hormone secreted into human cerebrospinal fluid (CSF), plasma and urine that promotes longevity and influences the onset of several premature senescent phenotypes in mice and humans, including atherosclerosis, cardiovascular disease, stroke and osteoporosis. Preliminary studies also suggest that Klotho possesses tumor suppressor properties. Klotho's roles in these phenomena were first suggested by studies demonstrating that a defect in the Klotho gene in mice results in a significant decrease in lifespan. The Klotho-deficient mouse dies prematurely at 8-9 weeks of age. At 4-5 weeks of age, a syndrome resembling human ageing emerges consisting of atherosclerosis, osteoporosis, cognitive disturbances and alterations of hippocampal architecture. Several deficits in Klotho-deficient mice are likely to contribute to these phenomena. These include an inability to defend against oxidative stress in the central nervous system and periphery, decreased capacity to generate nitric oxide to sustain normal endothelial reactivity, defective Klotho-related mediation of glycosylation and ion channel regulation, increased insulin/insulin-like growth factor signaling and a disturbed calcium and phosphate homeostasis accompanied by altered vitamin D levels and ectopic calcification. Identifying the mechanisms by which Klotho influences multiple important pathways is an emerging field in human biology that will contribute significantly to understanding basic physiologic processes and targets for the treatment of complex diseases. Because many of the phenomena seen in Klotho-deficient mice occur in depressive illness, major depression and bipolar disorder represent illnesses potentially associated with Klotho dysregulation. Klotho's presence in CSF, blood and urine should facilitate its study in clinical populations.

Translational Psychiatry (2016) 6, e876; doi:10.1038/tp.2016.135; published online 30 August 2016

\section{INTRODUCTION}

Klotho is the name of the Greek goddess who spins the web of time and regulates the span of life. In both humans and experimental animals, Klotho promotes longevity, while disturbances in Klotho levels or functions are associated with multiple senescent phenotypes. ${ }^{1-3}$ We will present an overview of the data regarding Klotho secretion in humans and its relationship to health and disease. The data in humans are highly concordant with findings in mice, and the homology between the human gene and the mouse gene exceeds $80 \%{ }^{4}$ Thus, the Klothodeficient mouse is likely to be a good model system for helping us understand the mechanisms by which Klotho works, and serves as a guide for further studies in humans.

The human Klotho gene was identified by Matsumura et al. Sequence analysis of the isolated human Klotho complementary DNA clones revealed that there were two transcripts that apparently arise from alternative RNA splicing. One transcript encodes a single-pass membrane protein, which has the same structure as the mouse Klotho protein. The other transcript is identical with the membrane form except for a $50 \mathrm{bp}$ insertion and encodes a putative secreted form of the Klotho protein. The secreted form of the transcript predominated over the membrane form in all the tissues examined. Thus, the major Klotho gene product is not the membrane protein, but, rather, the secreted protein. $^{4}$

In mice, the Klotho protein is cleaved by the alpha secretases, ADAM10 and ADAM 17, beta-secretase and b-amyloid precursor protein cleaving enzyme-1. ${ }^{5}$ This cleavage will eventually result in an ectodomain that is released into the systemic circulation, cerebrospinal fluid (CSF) and urine ${ }^{6,7}$ to potentially mediate the widespread humeral impacts of Klotho (Figure 1a). These include protection from oxidative stress ${ }^{8}$ and cancer, ${ }^{9}$ inhibition of insulinlike growth factor-1 (IGF-1)/insulin signaling ${ }^{10}$ and regulation of multiple ion channel activity such as transient receptor potential vaniloid 5 and 6 (TRPV5 and 6) calcium channels via its putative sialidase activity, ${ }^{11}$ as well as, widespread involvement in Wnt signaling ${ }^{12}$ and nitric oxide (NO) production. ${ }^{13}$

The full-length protein recruits $\mathrm{Na}^{+}, \mathrm{K}^{+}$-ATPase to the cell surface in response to hypocalcemic stimuli regulating the transepithelial $\mathrm{Ca}^{2+}$ transport in the brain choroid plexus and the kidney, as well as the PTH secretion from the parathyroid glands (Figure $1 \mathrm{~b}$ ). ${ }^{14}$ The full-length protein also functions as an obligatory co-receptor for fibroblast growth factor 23 (FGF23) converting canonical fibroblast growth factor receptor-1C into a specific receptor for FGF23. ${ }^{15}$ FGF23 negatively regulates blood phosphate, vitamin $\mathrm{D}^{16}$ and $\mathrm{PTH}^{17}$ levels. Eventually, Klotho is

${ }^{1}$ Clinical Neuroendocrinology Branch, National Institute of Mental Health, National Institutes of Health, Bethesda, MD, USA and ${ }^{2}$ Lipoprotein Metabolism Section, Cardiovascular and Pulmonary Branch, National Institute of Heart, Lung, and Blood Institute, National Institutes of Health, Bethesda, MD, USA. Correspondence: Dr PW Gold, Intramural NIH Research Program, National Institute of Mental Health, National Institutes of Health, Building 10, Clinical Center, Room 2D-46, 10 Center Drive MSC 1284, Bethesda, MD 208921284, USA. 


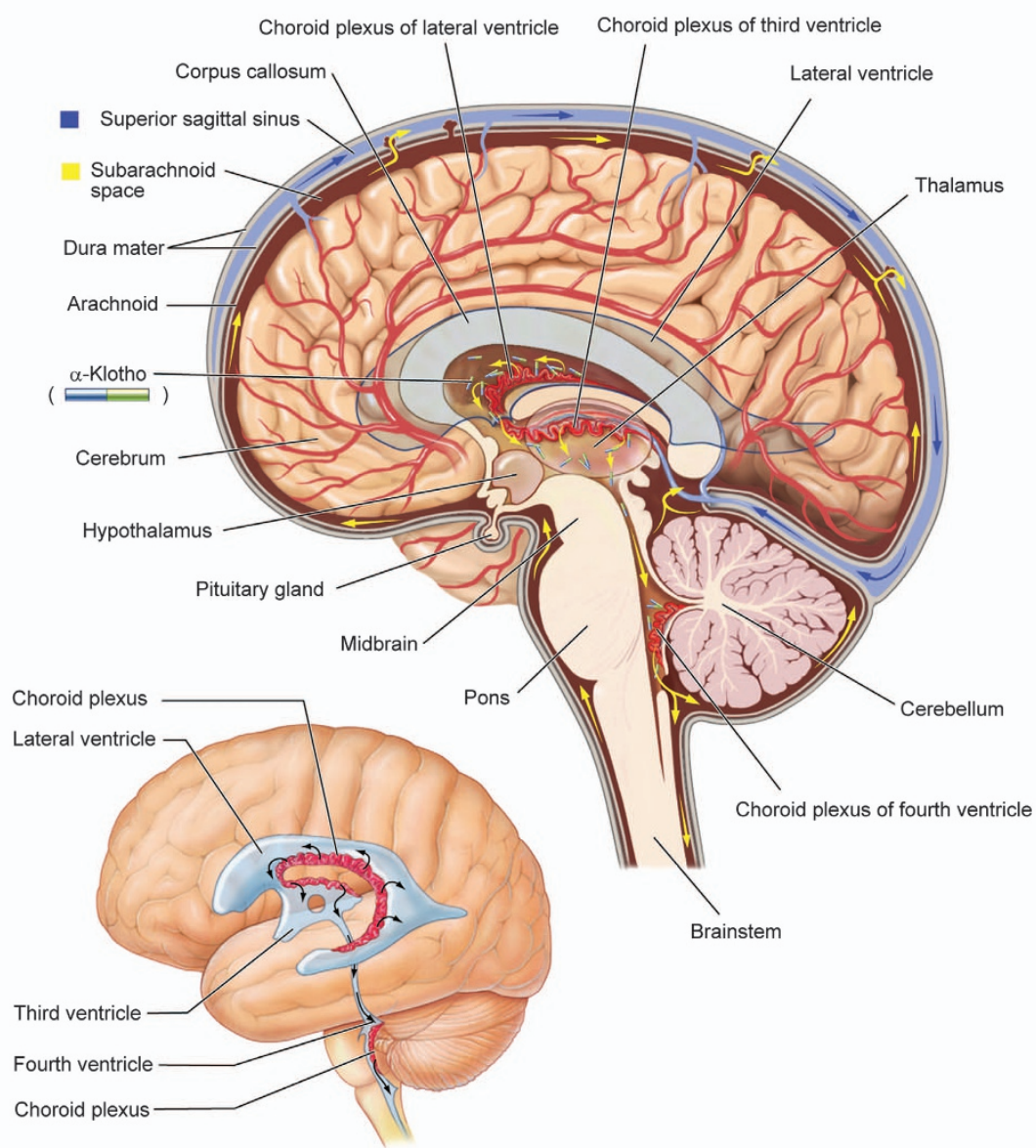

b

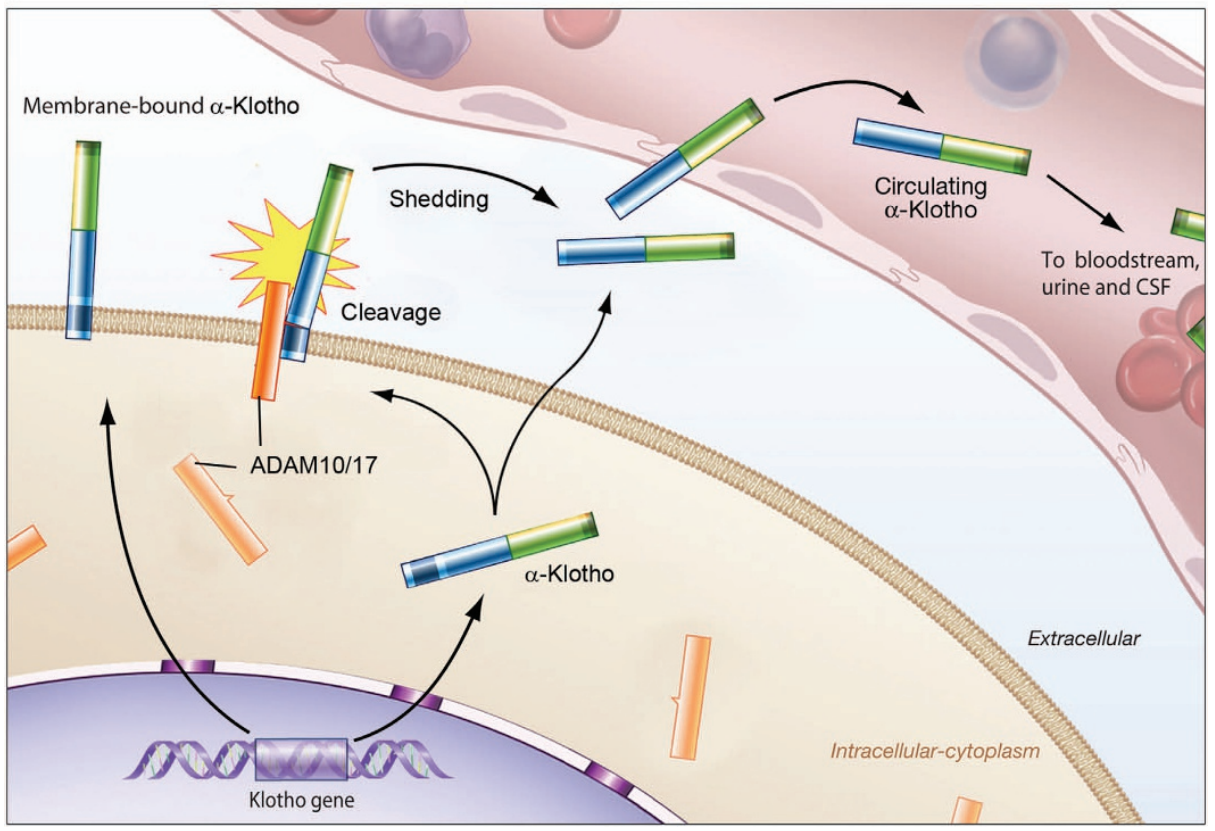

Figure 1. (a) Post-translation processing of Klotho protein. The transmembrane form of Klotho protein is thought to be processed by the $\alpha$ secretases ADAM10 and 17, as well as by the $\beta$-secretase by BACE1 ( $\beta$-APP cleaving enzyme-1). The remaining membrane-bound fragment is a substrate for regulated intramembrane proteolysis by $\gamma$-secretase. The cleaved ectodomain is released into the circulation from where it is thought to exert its potential humoral effects. (b) Klotho-dependent recruitment of the $\mathrm{Na}^{+}, \mathrm{K}^{+}$-ATPase to the cell surface in response to hypocalcemic stimuli. In alpha-Klotho (a-Klotho) expressing cells, hypocalcemia elicits a rapid response to securely restore normal calcium levels. This is achieved by massive $\mathrm{Na}^{+}, \mathrm{K}^{+}$-ATPase recruitment to the cell surface through a combination of the 'conventional pathway' and the 'a-Klotho-dependent pathway'. Alpha-Klotho is required for the rapid recruitment of $\mathrm{Na}^{+}, \mathrm{K}^{+}$-ATPase to the cell surface in response to low calcium levels which occurs in conjunction with the a-Klotho cleavage and release. CSF, cerebrospinal fluid. 


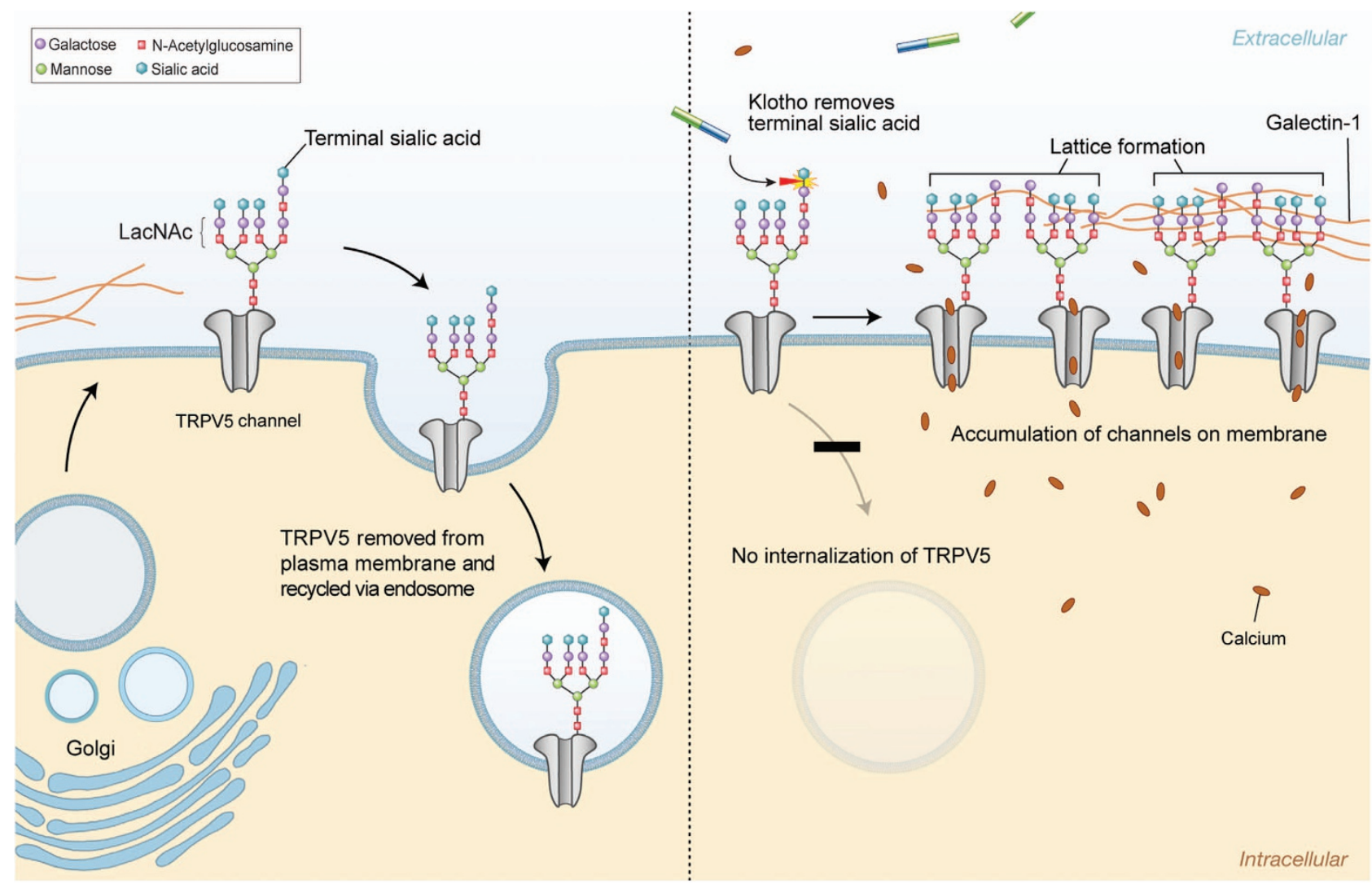

Figure 2. Klotho-mediated retention of TRPV5 on the cell surface. The number of TRPV5 channels on the cell membrane through which calcium influx is achieved is dependent on the final balance between two counterbalancing mechanisms: protein insertion via the Golgi apparatus and protein removal via endocytosis in endosomes. LacNac ( $N$-acetyllactosamine) is a ligand for galactin- 1 . Sialic acids prevent binding of LacNac to galectin-1. Removal of the terminal sialic acids from N-glycan of TRPV5 channels by secreted Klotho permits binding of LacNac to galecting-1 preventing channel endocytosis. That will eventually result in accumulation of TRPV5 on the cell surface and increased calcium flow into the cell. TRPV, transient receptor potential vaniloid.

involved in every step of fine-tuned time-dependent calcium regulation through multiple feedback loops that rapidly adjust extracellular calcium levels, maintaining its concentration within strictly narrow ranges. Thus, Klotho seems to have a central role in calcium homeostasis both in the CSF and in the periphery. ${ }^{18}$

\section{STUDIES OF KLOTHO IN NORMALS}

The normal levels of Klotho in humans, first reported by Yamazaki et al., ${ }^{19}$ range from 239 to $1266 \mathrm{pg} \mathrm{ml}^{-1}$ (mean \pm s.d.; $562 \pm 146 \mathrm{pg} \mathrm{ml}^{-1}$ ) and correlates positively with phosphate and negatively with age, calcium, FGF23, BUN and creatinine in blood. Klotho levels in children (mean \pm s.d.; $952 \pm 282 \mathrm{pg} \mathrm{ml}^{-1}$ ) are almost double (mean \pm s.d. $562 \pm 146),{ }^{19}$ whereas in the umbilical vein blood they are almost five times those in normal adults. ${ }^{20}$

\section{KLOTHO IN HUMAN LONGEVITY}

To determine the role of altered Klotho gene in longevity, Arking et al. ${ }^{1}$ conducted a search for functional variants of Klotho in three distinct populations consisting of newborn and elderly Bohemian Czechs, Baltimore Caucasians and Baltimore African Americans. In all the three groups, they identified an allele of Klotho, KL-VS, which was defined by six single-nucleotide polymorphisms (SNPs) in complete linkage disequilibrium. Allele-specific oligonucleotide hybridation revealed three mutations in exon 2, two of which resulted in amino acid substitutions. The change in amino acid at position 352 was a phenylalanine to valine, whereas the change in amino acid position 370 was a cysteine to serine substitution. Homozygosity for these mutations was significantly less frequent in the elderly than in newborns in all the three populations. In Bohemian Czechs, but not in Baltimore Caucasians or Baltimore African Americans, heterozygosity was more prevalent in the elderly suggesting a survival advantage. Kaplan-Meier survival curves stratified by the genotype showed a positive effect for lifespan in Bohemian Czechs older than 80 years who were heterozygous for the KL-VS allele. ${ }^{1}$

Multiple examples of heterozygote advantage in conjunction with homozygote disadvantage exist, including CFTR allele $\Delta \mathrm{F} 508$ (ref. 21) and hemoglobin S. ${ }^{22}$ Thus, the advantage in heterozygous status is highly dependent on the presence of specific environmental burdens, in contrast to homozygosity, which is not. The V352 substitution in Klotho gene is likely to be important because phenylalanine at this position is remarkably conserved in homologous proteins in eukaryotic organisms. Cysteine at the 370 position is only seen in the first family I glycosidase domain of human Klotho. This may interfere with Klotho function in glycosylation. Extracellular domain of Klotho increases cell surface abundance of TRPV5 by removing terminal sialic acids from their $\mathrm{N}$-linked glycan chains. This removal in turn, permits binding of galactose- $N$-acetyloglucosamine (LacNAc) to galectin-1 preventing channel endocytosis (Figure 2). ${ }^{23} \mathrm{~N}$-glycan-mediated binding to galectins is important in regulating the residence time of cell surface glycoproteins. Altered post-translational modification such as glycosylation has been implicated in the development of complex diseases such as type 2 diabetes, cancer metastasis and 
aging. $^{24-26}$ Many models of aging also indicate accelerated or excessive post-translational modification of proteins, lipids and nucleic acids. Under normal ambient sugar concentration, nonenzymatic condensation reactions, between reducing sugars and proteins or lipids and nucleic acids, (glycation) proceed slowly and the final products (advanced glycation end products-AGE) are efficiently eliminated from the circulation. During hyperglycemia, however, AGE and other glycotoxin production exceeds the detoxification ratio. Accumulation of these products becomes toxic for tissues and organs. ${ }^{27-29}$ It is possible that the glycosidase activity of Klotho contributing to the effective internalization and subsequent elimination of AGEs, inhibits the excess formation of AGEs and their deleterious effects on tissues.

Suppression of aging in Klotho transgenic mice has been attributed to Klotho ability to decrease the insulin/IGF-1 signaling by suppressing tyrosine phosphorylation of insulin and IGF-1 receptors thus, reducing signaling events downstream of receptor activation, including tyrosine-phosphorylated insulin receptor substrate 1 and 2 (IRS-1, IRS-2), and their association with the subunit of phosphoinositide 3-kinase p85. ${ }^{10}$ These data are compatible with the finding that IRS-1 knockout in mice significantly prolongs life. ${ }^{30}$ Extended lifespan upon negative regulation of insulin and IGF-1 signaling is an evolutionarily conserved mechanism to suppress aging. ${ }^{31}$ An additional potential mechanism is that a reduction in insulin-stimulated intracellular glucose availability potentially prevents intracellular lipid overload and lipotoxicity, a proposed mechanism in the lifeshortening metabolic syndrome. ${ }^{32}$ In this regard, it is thus possible that the mutations observed in the resultant KL-VS variant may alter Klotho levels or function contributing to the development and premature appearance of various diseases associated with increased morbidity and mortality.

\section{THE ROLE OF KLOTHO IN CARDIOVASCULAR DISEASE}

The premature death of Klotho-deficient mouse at 8-9 weeks of age was linked to the development of a syndrome resembling human ageing, at 4-5 weeks of age, consisting of premature atherosclerosis, osteoporosis, infertility, cognitive disturbances and alterations of hippocampal architecture. ${ }^{3,33,34}$

Lower plasma Klotho levels were independently associated with increased risk of cardiovascular disease in community-dwelling adults. The levels of Klotho in plasma were also positively associated with high-density lipoprotein cholesterol levels and negatively with age and C-reactive protein. ${ }^{35}$ To further determine the influence of Klotho to atherosclerotic risk in humans two independent samples that included individuals with documented cardiovascular disease and their healthy siblings, were studied. The KL-VS allele was an independent risk factor for occult coronary artery disease, as assessed by an exercise thalium tomography scan and/or an exercise electrocardiogram. Hypertension and increasing high-density lipoprotein levels masked or reduced the risk respectively and current smoking increased the risk. ${ }^{2}$

A heterozygosity advantage of the KL-VS allele with respect to cardiovascular risk factors and stroke was reported to a homogeneous population of 525 Ashkenazi Jews, like in the Bohemian Czechs. In this study, longevity was also positively affected. On the other hand, homozygosity was associated with the worst outcomes. $^{36}$ A homozygosity disadvantage with higher stroke incidence compared with heterozygotes in subjects younger than 40 years of age was also reported for the KI-VS polymorphism. ${ }^{37}$ Several other polymorphisms of human Klotho gene have been recently associated with alterations in cardiovascular function and increase susceptibility to coronary artery disease. The Klotho SNP rs650439, was significantly associated with mean carotid artery intima-media thickness and carotid atherosclerosis in hypertensive subjects suggesting that the Klotho SNP rs650439 may affect the progression of atherosclerosis in hypertensive patients. ${ }^{38}$ Another
Klotho SNP, the G395 was also found to be associated with systolic blood pressure in healthy Japanese women. ${ }^{39}$ The same SNP was found to be an independent risk factor for atherosclerotic coronary artery disease. ${ }^{40}$ Subjects older than 40 years with the C1818T variant of Klotho gene were found to have lower plasma NO levels, suggesting an age-specific effect of Klotho C1818T variant, which becomes pronounced with age. ${ }^{41}$

Decreased bioavailability of NO contributes to vascular endothelial dysfunction, the initial step in the development of atherosclerosis. ${ }^{42}$ Endothelial dysfunction occurs when endothelial cells lose their ability to defense against thrombosis and inflammation in response to various metabolic and environmental stressors. ${ }^{43}$ Increased production of reactive oxygen species, impaired endothelium-dependent vasorelaxation, high intracellular calcium levels, increased endothelial permeability and increased expression of adhesion molecules, cytokines and chemokines that augment leucocyte diapedesis and platelet aggregation, in addition to decreased NO production, constitutes endothelial dysfunction. ${ }^{44,45}$

Klotho seems to have a positive role in endothelium physiology ameliorating endothelial dysfunction through multiple pathways. ${ }^{35}$ The Klotho-deficient mouse shows decreased NO biosynthesis and impaired vasodilation. Endothelial function can be restored by parabiosis with wild-type mice. ${ }^{13}$ In Otsuka Long-Evans Tokushima Fatty Rat, an animal model of atherosclerotic disease, which demonstrates multiple atherogenic risk factors including hypertension, obesity, severe hyperglycemia and dyslipidemia, adenovirus-mediated Klotho gene delivery ameliorated vascular endothelial dysfunction, increased NO production, reduced elevated blood pressure, and prevented medial hypertrophy and perivascular fibrosis. $^{46}$

In vitro, Klotho induces NO production in human umbilical vein endothelial cells via activation of c-AMP-PKA pathway. The activation of c-AMP pathway by Klotho also induces a two-fold increase in manganese superoxide dismutase (Mn-SOD) expression, either directly or through increased NO production. ${ }^{47}$

Circulating Klotho confers increased resistance to oxidative stress through its ability to inhibit insulin/IGF-1 signaling, downstream targets of which are FoxO forkhead transcription factors (FOXOs). Binding of Klotho protein to cell surface receptors signals inhibition of FOXO phosphorylation and promotes its nuclear translocation. The nuclear FOXO then directly binds to the SOD2 promoter, and upregulates its expression, facilitating removal of reactive oxygen species. Possibly Klotho also activates FOXO not only by inhibiting Akt, but also through inhibiting SGK and/or activating JNK or beta-catenin. ${ }^{8}$ Crossing the Klotho-deficient mouse with a mouse heterozygous for deletion of IRS-1 rescues the arteriosclerotic phenotype. ${ }^{10}$

Klotho in the systemic circulation maintain endothelial integrity by regulating transient receptor potential canonical-1-mediated calcium entry in endothelial cells. Klotho binds to both vascular endothelial growth factor receptor-2 and TPRC1 complex mediating their internalization after vascular endothelial growth factor stimulation thus regulating transient receptor potential canonical1 expression level on the plasma membrane. In Klotho-deficient mice, calcium influx is aberrant resulting in vascular hyperpermeability with increased apoptosis owing to decreased expression of endothelial cadherin and activation of calcium-dependent proteases, calpain and caspase-3. ${ }^{48}$ Cellular apoptosis and vascular cell senescence was attenuated in human umbilical vein endothelial cells when treated with Klotho recombinant protein. Klotho mediated this effect by inducing transient phosphorylation of mitogen-activated kinases. ${ }^{49}$

Klotho may also buffer against endothelial inflammation. Thus, Klotho inhibited downstream effects of tumor necrosis factor-a, such as activation of the expression of intracellular and vascular cell adhesion molecules ICAM- 1 and VCAM- 1 in human umbilical vein endothelial cells and the rat aorta. Furthermore, Klotho 
inhibited NF-kB activation, IkB phosphorylation, tumor necrosis factor-a induced inhibition of eNOS phosphorylation, and monocyte adhesion to human umbilical vein endothelial cells. ${ }^{50}$

\section{KLOTHO IN OSTEOPOROSIS}

Two SNPs, G395 and C1818T associated with cardiovascular disease were also found to be associated with bone mineral density in women but contradictive results exist regarding the age prevalence of this association. ${ }^{39}$ The contribution of a microsatellite polymorphism at the human Klotho locus to bone density and spondylosis of the lumbar spine in healthy Japanese postmenopausal women was also investigated by Ogata et al. ${ }^{51}$ Two types of alleles were associated with bone density in the older population, whereas another distant allele was associated with spondylosis in the younger population, suggesting the relationship of Klotho to etiology of osteoporosis and spondylosis in independent ways. $^{51}$

A complex repertoire of systemic and local factors contributes to bone health, dysregulation of which results in increased bone loss and the clinical manifestations of osteoporosis. ${ }^{52,53}$ Until the discovery of Klotho, the only widely accepted mediators of calcium metabolism consisted of PTH, the calcium receptor, calcitonin and vitamin D..$^{5,55}$ The discovery of Klotho, and the closely related compound FGF23, added a pronounced new levels of regulation that are as equally important to any of those that have already been the object of extensive study. ${ }^{56}$ Klotho has key roles in the tuning of calcium extracellular concentration maintaining normal plasma calcium levels in the context of either hypo- or hypercalcemia in an exceedingly tight range. ${ }^{18}$

In response to hypocalcemia, over the course of seconds to minutes the full-length Klotho facilitates the transport of $\mathrm{Na}^{+}, \mathrm{K}^{+}$ATPase to the cell membrane of the parathyroid gland and distal convoluted tubule (DCT) of the kidneys ${ }^{14,55}$ (Figure 2b). This creates an electrochemical gradient that eventually triggers PTH secretion and the rapid renal transepithelial transport of calcium, respectively. In kidney, this effect occurs in cooperation with TRPV5, a major renal calcium channel, calbindin-D28k and sodiumcalcium exchanger-1 (NCX-1), all of which are exclusively coexpressed with Klotho at the DCT. Thus, in Klotho-deficient mice, the PTH response to experimentally induced low calcium levels was significantly reduced by approximately $75 \%$, whereas both the direct and the PTH-mediated active reabsorption of calcium is impaired, resulting in the excess excretion of calcium in the urine even though plasma calcium levels are increased. ${ }^{14,18,57}$ The PTHmediated increase in plasma calcium levels, such as calcium reabsorption in kidney, and calcium resorption in the bones continues over a somewhat longer period meaning from minutes to hours. ${ }^{58}$ Parathyroid hormone also stimulates vitamin D production that in turn mediates intestinal calcium uptake. ${ }^{59}$ The principal effect of vitamin D is the enhancement of intestinal calcium absorption, an effect that is mediated over the course of hours to days. ${ }^{60}$ In addition, vitamin D enhances TRPV 5 expression and function on the apical membrane of DCT cells, and thereby upregulates calcium reabsorption in the kidney. ${ }^{11,61}$

In turn, increased calcium suppresses the rapid transepithelial calcium transport and PTH secretion, as well as, increased vitamin $D$ levels suppresses 1a-hydroxylase gene expression both by self negative feedback regulation and via Klotho/FGF23-dependent pathway, limiting that way further increase in plasma calcium concentration. $^{62}$ Klotho converts bone-derived FGF23 to a receptor specific for FGF receptor-1c at the DCT. This binding allows FGF23 to decrease 1a-hydroxylase expression in the kidney, which encodes the rate-limiting enzyme in vitamin $D$ synthesis. $^{15,16,63}$ FGF23, produced by the bone, thus becomes the pivotal component in a newly discovered bone-kidney-parathyroid axis for the regulation of calcium metabolism (Figure 3).
FGF23-deficient mice show a phenotype virtually identical to that of the Klotho-deficient mouse. ${ }^{64,65}$

In the Klotho-deficient mouse, the net effect of the absent Klotho results in increased plasma calcium and phosphorus concentrations. This largely reflects the absence of Klotho for enabling FGF23 to inhibit vitamin D levels. Hence giving high vitamin $D$ levels seemed to outweigh the consequences of the rapid effects of Klotho to mobilize calcium through mainly its reabsorption in the kidney. ${ }^{66}$ The net effect of Klotho deficiency on bone metabolism is to result in an osteoporotic picture similar to that seen with aging. ${ }^{67-69}$

Local factors such as cytokines strongly regulate bone cell function and have a major role in bone remodeling and structure. Osteoporosis, as well as other age-related phenotypes, are all considered as chronic inflammatory diseases. ${ }^{70,71}$ Indeed, many tissues in Klotho-deficient mice express and secrete more inflammatory factors and accumulate more interleukin- 6 in serum compared with wild type. It was recently shown that the intracellular form of Klotho suppresses retinoic-acid-inducible gene-l-induced expression of interleukin- 6 and interleukin- 8 both in vivo and in vitro, uncovering a possible new mechanism of Klotho-mediated inhibition of senescence-associated inflammation and development of chronic inflammatory diseases such as osteoporosis. $^{72}$

\section{KLOTHO AND THE KIDNEY DISEASE}

Klotho is abundantly expressed in the distal nephron where it regulates mineral metabolism. ${ }^{14,73}$ It is also present in the proximal tubule lumen where directly or more possibly from the DCT, it inhibits phosphorous reabsorption by modulating $\mathrm{Na}$ coupled Pi transporters via enzymatic glycan modification of the transporter proteins. ${ }^{74,75}$ Acute kidney injury and chronic kidney disease (CKD) are states of systemic Klotho deficiency, suggesting that Klotho is involved in the pathogenesis of renal disease. Klotho deficiency exacerbates kidney injury and decreases markers of renal function, whereas Klotho delivery or increased expression acts as a renoprotective factor, in animal models of both acute kidney injury and CKD. ${ }^{76,77}$ Renoprotective effects of Klotho has been attributed to its antioxidant, anti-inflammatory and antiapoptotic properties. ${ }^{78-80}$

In humans, a recent study on CKD patients of various stages and healthy people, showed that there is a progressive decrease in secreted Klotho protein in urine occurring during progression of the disease. The decrease of Klotho in urine becomes apparent even in the early stage 1-2 in CKD patients with the lowest values being detected in stage 5 . Thus, Klotho measurement in urine could potentially serve as an early biomarker of CKD. ${ }^{7}$

Klotho-deficient mice show hyperphosphatemia and hypercalcemia, decreased renal function, osteopenia and severe calcification. $^{3}$ Aberrant mineral metabolism is implicated in hyperparathyroidism, osteodystrophy and vascular calcification in CKD. ${ }^{81-84}$

Soft tissue calcification, and especially vascular calcification, is one of the most prominent and severe complications of CKD, associated with high mortality. ${ }^{85-87}$ For this reason, CKD is included in the highest risk group for cardiovascular disease. ${ }^{88}$ As in Klotho-deficient mice, CKD patients show high levels of phosphorus. Phosphorus overload aggravates calcification, whereas lowering phosphorus levels reduces calcification in these patients. ${ }^{89,90}$ Klotho seems to protect against soft tissue calcification mainly through three mechanisms: phosphaturia, preservation of renal function and a direct effect on vascular smooth muscle cells by inhibiting phosphate uptake and dedifferentiation. $7,74-76,78,91$ The osteopenia described in Klotho mice is a state of low bone turnover. ${ }^{92}$ Consistently, a low turnover bone condition has been reported in CKD suggesting that Klotho deficiency may be also related to renal osteodystrophy. ${ }^{93,94}$ Koh 


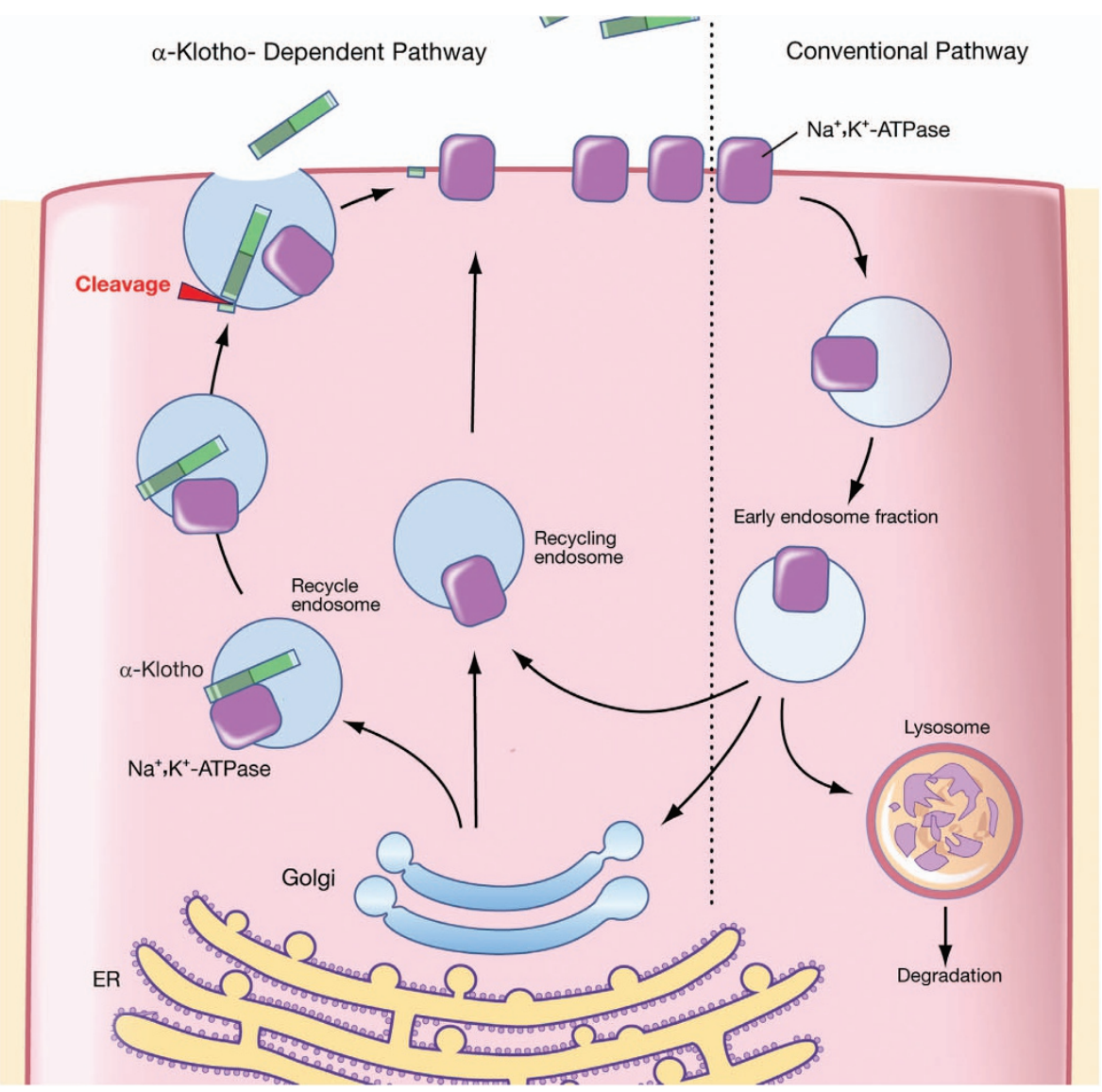

Figure 3. The bone-kidney-parathyroid axes. Negative feedback loops in the regulation of calcium metabolism. Increased levels of 1,25 (OH) 2D3-the active form of vitamin D-bind to the vitamin D receptor (VDR) in osteocytes, which, in turn, forms a heterodimer with the nuclear receptor RXR. The complex afterwards directly binds to the promoter area of FGF23 gene and activates its expression. Secretion of FGF23 protein from bone suppresses further synthesis of vitamin D by either binding to the Klotho-FGFR complex in the parathyroids (boneparathyroid axis) or by binding to the same complex in kidneys (bone-kidney axis). In the parathyroid gland, FGF23 suppresses PTH expression, which, in turn, suppresses the expression of $\mathrm{Cyp} 27 \mathrm{~b} 1$ gene that encodes $1 \mathrm{a}$-hydroxylase, the rate-limiting enzyme in 1,25 (OH)2D3 synthesis. In the kidney-bone axis, FGF23 directly suppresses Cyp27b1 gene expression. Alpha-Klotho is required to convert the canonical FGF receptor-1c (FgfR1c) to a receptor specific for FGF23. FGF, fibroblast growth factor.

et $a l .{ }^{95}$ studied the possible involvement of Klotho in complications arising in patients with chronic renal failure. They examined the kidneys of 10 clinically or histologically diagnosed chronic renal failure cases. Both the expression of Klotho mRNA and the levels of Klotho protein was greatly reduced in chronic renal failure kidneys. ${ }^{95}$

\section{KLOTHO IN HUMAN CANCER DEVELOPMENT}

Accumulated evidence implicates Klotho in the development and progression of several different human cancers, including breast, cervical, colorectal, gastric and lung carcinomas.9,96-99 In 2008, Wolf et al., ${ }^{9}$ identified for the first time tumor suppressor activities for Klotho in breast cancer. Breast cancer tissue expressed significantly less Klotho than normal breast tissue. In cancer samples, high Klotho expression was associated with smaller tumor size. In addition, forced expression of Klotho or soluble Klotho treatment slowed cancer cell growth, whereas Klotho silencing enhanced proliferation. This was associated with inhibition of IGF-1/insulin pathway, upregulation of the tumor suppressor C/EBPbeta, p53 and FGF pathway by bFGF, in a cellspecific manner. ${ }^{9}$ In Ashkenazi Jewish women carriers of BRCA1 mutation, heterozygosity for the Klotho functional variant KL-VS was associated with increased risk for breast and ovarian cancers, as well as with younger age at diagnosis of breast cancer. It is possible that the KL-VS variant results in decreased shedding of the Klotho that halts its proliferation inhibitory activities. ${ }^{100}$ These data were later verified for other tumors such as lung and pancreatic cancer. ${ }^{99,101}$ Furthermore, in pancreatic cancer, Klotho and the $\mathrm{KI} 1$ domain of Klotho administration in mice, were equally antiproliferative though the KL1 domain had a more favorable safety profile. $^{101}$

Promoter DNA methylation is an epigenetic change that induces inactivation of tumor suppressor genes facilitating the aberrant cell growth. ${ }^{102}$ Consistently, Klotho gene promoter methylation was frequently detected in gastric and colorectal cancers where Klotho expression was also significantly reduced. Promoter methylation of Klotho was significantly associated with a poor outcome in gastric carcinoma patients and demethylation with 5-aza-2'-deoxycytidine increased Klotho expression. Furthermore, ectopic expression of Klotho led to the cell proliferation inhibition of colon cancer cell lines via the induction of cell apoptosis and $\mathrm{S}$ phase cycle arrest. ${ }^{97,98}$ In cervical cancer, these epigenetic aberrations of Klotho associated with promoter hypermethylation may occur at the late phase of cervical tumorigenesis and result in loss of Klotho function as a Wnt antagonist. ${ }^{96}$ Uncontrolled activation of canonical Wnt signaling is thought to have a crucial role during carcinigenesis. ${ }^{103}$ 


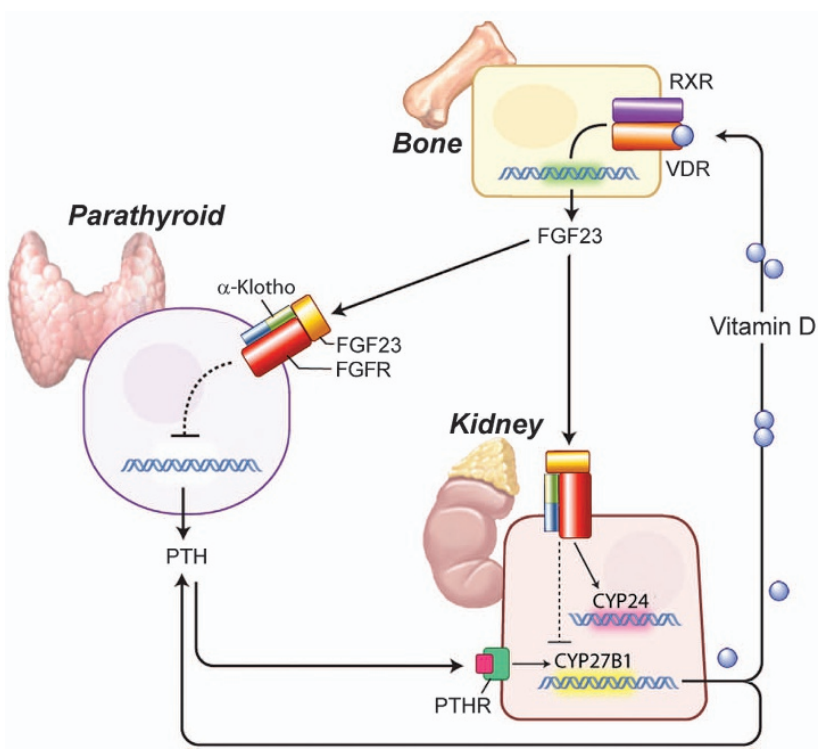

Figure 4. Klotho expression in brain. The highest expression of Klotho in brain is observed in chorioid plexus of both lateral and third ventricles. It is predominantly localized at the apical membrane of ependymal cells which faces the ventricles. FGF23, fibroblast growth factor 23; VDR, vitamin D receptor.

\section{KLOTHO IN CENTRAL NERVOUS SYSTEM AND CENTRAL NERVOUS SYSTEM-RELATED DISORDERS}

To our knowledge, the role of Klotho in the human central nervous system and ts association with disease has notion studied directly. A single study of 804 subjects over 65 designed simply to compare lower and upper tertiles of Klotho levels reported that those in the lowest tertile had a significant increase in all-cause mortality and significantly greater cognitive impairment, as assessed by a MiniMental State examination score of less than $24 .^{104}$

In mice, the choroid plexus is the sole site for Klotho localization in brain (Figure 4). ${ }^{73}$ Confocal microscopy reveals that it is mainly localized at the apical plasma membrane of ependymal cells, which face the ventricles. In mouse choroid cells, the full-length Klotho protein facilitates the transport of $\mathrm{Na}^{+}, \mathrm{K}^{+}$-ATPase creating a sodium gradient that possibly, in concert with calcium-binding proteins (NCX-1) and calcium channels (TRPV4) promotes calcium export into the CSF. ${ }^{14,105}$ It should be noted that though the Klotho-deficient mouse has a slightly increased plasma calcium levels, CSF calcium levels are significantly reduced being $27.3 \%$ lower than in WT mice. ${ }^{14}$

The Klotho-deficient mouse also shows an increase in mediators of oxidative stress in hippocampus at 5 weeks of age followed by a significant impairment of cognitive function at 7 weeks of age. The cognitive impairment and the lipid peroxide accumulation were prevented by a-tocopherol administration. ${ }^{33}$ At CA3 area of hippocampus, a decrease in the number of nerve terminals and the expression of synaptophysin, which is a marker for synaptic vesicles was also evident. ${ }^{73}$ Furthermore, neuronal degeneration was shown in hippocampal pyramidal cells and Purkinje cells, whereas at the anterior horn cells in the spinal cord, a decreased number of large neurons was also observed. ${ }^{34,106}$

Disturbed calcium homeostasis in neurons is associated with neuronal degeneration and death, a process that can proceed either rapidly (stroke) or slowly (Alzheimer's disease). ${ }^{107,108}$ Recently, Klotho and transtherytin were shown to be activated by soluble amyloid precursor protein (APP)- $\beta$ products possibly facilitating APPbeta sequestration. ${ }^{109}$ It is also possible that the same mechanisms that increase oxidative defense in the periphery, such as suppression of IGF-1/insulin axis, increased
NO production, inhibition of inflammatory mediators, are also activated in the central nervous system. Recent data show that brain specific knockout of IRS-2 mouse leads to a longer lifespan through activation of FoXO transcription factors and SOD production. $^{110}$

Klotho lies at the intersection of multiple pathways that influence longevity and susceptibility to complex disorders such as atherosclerosis, osteoporosis, cancer, metabolic syndrome and diseases of neurodegeneration. Clinical studies of Klotho have merely scratched the surface of a whole new area of further research into the mechanisms governing fundamental pathways such as those involved in insulin and calcium metabolism, mechanisms of oxidative stress and the pathogenesis of multiple complex disorders. In addition to classic diseases of neurodegeneration, many of the consequences of Klotho deficiency occur in depressive illness, including premature coronary disease, atherosclerosis and osteoporosis, decreased lifespan and similar changes in hippocampal structure. Thus, alterations in Klotho function may emerge as an important marker for predicting susceptibility to subsequent illness and as a valuable tool in therapeutics. Even basic properties such as the pattern of Klotho's possible pulsatile secretion and diurnal variation remain to be elucidated.

\section{CONFLICT OF INTEREST}

The authors declare no conflict of interest.

\section{REFERENCES}

1 Arking DE, Krebsova A, Macek M Sr, Macek M Jr, Arking A, Mian IS et al. Association of human aging with a functional variant of klotho. Proc Natl Acad Sci USA 2002; 99: 856-861.

2 Arking DE, Becker DM, Yanek LR, Fallin D, Judge DP, Moy TF et al. KLOTHO allele status and the risk of early-onset occult coronary artery disease. Am J Hum Genet 2003; 72: 1154-1161.

3 Kuro-o M, Matsumura Y, Aizawa H, Kawaguchi H, Suga T, Utsugi T et al. Mutation of the mouse klotho gene leads to a syndrome resembling ageing. Nature 1997; 390: 45-51.

4 Matsumura Y, Aizawa H, Shiraki-lida T, Nagai R, Kuro-o M, Nabeshima Y. Identification of the human klotho gene and its two transcripts encoding membrane and secreted klotho protein. Biochem Biophys Res Commun 1998; 242: 626-630.

5 Chen CD, Podvin S, Gillespie E, Leeman SE, Abraham CR. Insulin stimulates the cleavage and release of the extracellular domain of Klotho by ADAM10 and ADAM17. Proc Natl Acad Sci USA 2007; 104: 19796-19801.

6 Imura A, Iwano A, Tohyama O, Tsuji Y, Nozaki K, Hashimoto N et al. Secreted Klotho protein in sera and CSF: implication for post-translational cleavage in release of Klotho protein from cell membrane. FEBS Lett 2004; 565: 143-147.

7 Hu MC, Shi M, Zhang J, Quinones H, Griffith C, Kuro-o M et al. Klotho deficiency causes vascular calcification in chronic kidney disease. J Am Soc Nephrol 2011; 22: $124-136$.

8 Yamamoto M, Clark JD, Pastor JV, Gurnani P, Nandi A, Kurosu H et al. Regulation of oxidative stress by the anti-aging hormone klotho. J Biol Chem 2005; 280: 38029-38034.

9 Wolf I, Levanon-Cohen S, Bose S, Ligumsky H, Sredni B, Kanety H et al. Klotho: a tumor suppressor and a modulator of the IGF-1 and FGF pathways in human breast cancer. Oncogene 2008; 27: 7094-7105.

10 Kurosu H, Yamamoto M, Clark JD, Pastor JV, Nandi A, Gurnani P et al. Suppression of aging in mice by the hormone Klotho. Science 2005; 309: 1829-1833.

11 Chang Q, Hoefs S, van der Kemp AW, Topala CN, Bindels RJ, Hoenderop JG. The beta-glucuronidase klotho hydrolyzes and activates the TRPV5 channel. Science 2005; 310: 490-493.

12 Liu H, Fergusson MM, Castilho RM, Liu J, Cao L, Chen J et al. Augmented Wnt signaling in a mammalian model of accelerated aging. Science 2007; 317: 803-806.

13 Saito Y, Yamagishi T, Nakamura T, Ohyama Y, Aizawa H, Suga T et al. Klotho protein protects against endothelial dysfunction. Biochem Biophys Res Commun 1998; 248: 324-329.

14 Imura A, Tsuji Y, Murata M, Maeda R, Kubota K, Iwano A et al. alpha-Klotho as a regulator of calcium homeostasis. Science 2007; 316: 1615-1618.

15 Urakawa I, Yamazaki Y, Shimada T, lijima K, Hasegawa H, Okawa K et al. Klotho converts canonical FGF receptor into a specific receptor for FGF23. Nature 2006; 444: $770-774$. 
16 Shimada T, Hasegawa H, Yamazaki Y, Muto T, Hino R, Takeuchi Y et al. FGF-23 is a potent regulator of vitamin $\mathrm{D}$ metabolism and phosphate homeostasis. J Bone Miner Res 2004; 19: 429-435.

17 Krajisnik T, Bjorklund P, Marsell R, Ljunggren O, Akerstrom G, Jonsson KB et al. Fibroblast growth factor-23 regulates parathyroid hormone and 1alphahydroxylase expression in cultured bovine parathyroid cells. J Endocrinol 2007; 195: $125-131$.

18 Nabeshima $\mathrm{Y}$, Imura $\mathrm{H}$. alpha-Klotho: a regulator that integrates calcium homeostasis. Am J Nephrol 2008; 28: 455-464.

19 Yamazaki Y, Imura A, Urakawa I, Shimada T, Murakami J, Aono Y et al. Establishment of sandwich ELISA for soluble alpha-Klotho measurement: agedependent change of soluble alpha-Klotho levels in healthy subjects. Biochem Biophys Res Commun 2010; 398: 513-518.

20 Ohata Y, Arahori H, Namba N, Kitaoka T, Hirai H, Wada K et al. Circulating levels of soluble alpha-Klotho are markedly elevated in human umbilical cord blood. J Clin Endocrinol Metab 2011; 96: E943-E947.

21 Schroeder SA, Gaughan DM, Swift M. Protection against bronchial asthma by CFTR delta F508 mutation: a heterozygote advantage in cystic fibrosis. Nat Med 1995; 1: 703-705.

22 Roth EF Jr., Friedman M, Ueda Y, Tellez I, Trager W, Nagel RL. Sickling rates of human AS red cells infected in vitro with Plasmodium falciparum malaria. Science 1978; 202: 650-652.

23 Cha SK, Ortega B, Kurosu H, Rosenblatt KP, Kuro OM, Huang CL. Removal of sialic acid involving Klotho causes cell-surface retention of TRPV5 channel via binding to galectin-1. Proc Natl Acad Sci USA 2008; 105: 9805-9810.

24 Ohtsubo K, Takamatsu S, Minowa MT, Yoshida A, Takeuchi M, Marth JD. Dietary and genetic control of glucose transporter 2 glycosylation promotes insulin secretion in suppressing diabetes. Cell 2005; 123: 1307-1321.

25 Ohtsubo K, Marth JD. Glycosylation in cellular mechanisms of health and disease. Cell 2006; 126: 855-867.

26 Partridge EA, Le Roy C, Di Guglielmo GM, Pawling J, Cheung P, Granovsky M et al. Regulation of cytokine receptors by Golgi N-glycan processing and endocytosis. Science 2004; 306: 120-124.

27 Bierhaus A, Hofmann MA, Ziegler R, Nawroth PP. AGEs and their interaction with AGE-receptors in vascular disease and diabetes mellitus. I. The AGE concept. Cardiovasc Res 1998; 37: 586-600.

28 Uribarri J, Cai W, Peppa M, Goodman S, Ferrucci L, Striker G et al. Circulating glycotoxins and dietary advanced glycation endproducts: two links to inflammatory response, oxidative stress, and aging. J Gerontol A Biol Sci Med Sci 2007; 62: 427-433.

29 Vlassara H, Li YM, Imani F, Wojciechowicz D, Yang Z, Liu FT et al. Identification of galectin-3 as a high-affinity binding protein for advanced glycation end products (AGE): a new member of the AGE-receptor complex. Mol Med 1995; 1: 634-646.

30 Selman C, Lingard S, Choudhury Al, Batterham RL, Claret M, Clements M et al. Evidence for lifespan extension and delayed age-related biomarkers in insulin receptor substrate 1 null mice. FASEB J 2008; 22: 807-818.

31 Tatar M, Bartke A, Antebi A. The endocrine regulation of aging by insulin-like signals. Science 2003; 299: 1346-1351.

32 Unger RH. Klotho-induced insulin resistance: a blessing in disguise? Nat Med 2006; 12: 56-57.

33 Nagai T, Yamada K, Kim HC, Kim YS, Noda Y, Imura A et al. Cognition impairment in the genetic model of aging klotho gene mutant mice: a role of oxidative stress. FASEB J 2003; 17: 50-52.

34 Shiozaki M, Yoshimura K, Shibata M, Koike M, Matsuura N, Uchiyama Y et al. Morphological and biochemical signs of age-related neurodegenerative changes in klotho mutant mice. Neuroscience 2008; 152: 924-941.

35 Semba RD, Cappola AR, Sun K, Bandinelli S, Dalal M, Crasto C et al. Plasma Klotho and cardiovascular disease in adults. J Am Geriatr Soc 2011; 59: 1596-1601.

36 Arking DE, Atzmon G, Arking A, Barzilai N, Dietz HC. Association between a functional variant of the KLOTHO gene and high-density lipoprotein cholesterol, blood pressure, stroke, and longevity. Circ Res 2005; 96: 412-418.

37 Majumdar V, Nagaraja D, Christopher R. Association of the functional KL-VS variant of Klotho gene with early-onset ischemic stroke. Biochem Biophys Res Commun 2010; 403: 412-416.

38 Oguro R, Kamide K, Kokubo Y, Shimaoka I, Congrains A, Horio T et al. Association of carotid atherosclerosis with genetic polymorphisms of the klotho gene in patients with hypertension. Geriatr Gerontol Int 2010; 10: 311-318.

39 Shimoyama Y, Nishio K, Hamajima N, Niwa T. KLOTHO gene polymorphisms G-395 A and C1818T are associated with lipid and glucose metabolism, bone mineral density and systolic blood pressure in Japanese healthy subjects. Clin Chim Acta 2009; 406: 134-138.

40 Imamura A, Okumura K, Ogawa Y, Murakami R, Torigoe M, Numaguchi $Y$ et al. Klotho gene polymorphism may be a genetic risk factor for atherosclerotic coronary artery disease but not for vasospastic angina in Japanese. Clin Chim Acta 2006; 371: 66-70.
41 Majumdar V, Jose D, Christopher R. Influence of Klotho genotypes on plasma NO (x) levels in South Indian population. Thromb Res 2011; 128: 251-255.

42 Davignon J, Ganz P. Role of endothelial dysfunction in atherosclerosis. Circulation 2004; 109: III27-III32.

43 Esper RJ, Nordaby RA, Vilarino JO, Paragano A, Cacharron JL, Machado RA. Endothelial dysfunction: a comprehensive appraisal. Cardiovasc Diabetol 2006; 5: 4.

44 Ross R. Atherosclerosis_an inflammatory disease. N Engl J Med 1999; 340: 115-126.

45 Sitia S, Tomasoni L, Atzeni F, Ambrosio G, Cordiano C, Catapano A et al. From endothelial dysfunction to atherosclerosis. Autoimmun Rev 2010; 9: 830-834.

46 Saito Y, Nakamura T, Ohyama Y, Suzuki T, lida A, Shiraki-lida T et al. In vivo klotho gene delivery protects against endothelial dysfunction in multiple risk factor syndrome. Biochem Biophys Res Commun 2000; 276: 767-772.

47 Rakugi H, Matsukawa N, Ishikawa K, Yang J, Imai M, Ikushima M et al. Antioxidative effect of Klotho on endothelial cells through cAMP activation. Endocrine 2007; 31: 82-87.

48 Kusaba T, Okigaki M, Matui A, Murakami M, Ishikawa K, Kimura T et al. Klotho is associated with VEGF receptor-2 and the transient receptor potential canonical-1 Ca2+ channel to maintain endothelial integrity. Proc Natl Acad Sci USA 2010; 107: 19308-19313.

49 Maekawa Y, Ohishi M, Ikushima M, Yamamoto K, Yasuda O, Oguro R et al. Klotho protein diminishes endothelial apoptosis and senescence via a mitogenactivated kinase pathway. Geriatr Gerontol Int 2011; 11: 510-516.

50 Maekawa Y, Ishikawa K, Yasuda O, Oguro R, Hanasaki H, Kida I et al. Klotho suppresses TNF-alpha-induced expression of adhesion molecules in the endothelium and attenuates NF-kappaB activation. Endocrine 2009; 35: 341-346.

51 Ogata N, Matsumura Y, Shiraki M, Kawano K, Koshizuka Y, Hosoi T et al. Association of klotho gene polymorphism with bone density and spondylosis of the lumbar spine in postmenopausal women. Bone 2002; 31: 37-42.

52 Pacifici R. Estrogen, cytokines, and pathogenesis of postmenopausal osteoporosis. J Bone Miner Res 1996; 11: 1043-1051.

53 Marie PJ, Kassem M. Extrinsic mechanisms involved in age-related defective bone formation. J Clin Endocrinol Metab 2011; 96: 600-609.

54 Bilezikian JP, Marcus R, Levine MA. Physiological aspects of the parathyroid. In: Bilezikian JP, Marcus R, Levine MA (eds). The Parathyroids: Basic and Clinical Concepts. Academic Press: New York, NY, USA, 2003, pp 167-291.

55 Wilson JD, Foster DW, Kronenberg HM, Larsen PR. Hormones and disorders of mineral metabolism. In: Bringhurst FR, Demay M, Kronenberg HM (eds). Williams Text-book of Endocrinology. Saunders: Philadelphia, PA, USA, 2003, pp 1303-1371.

56 Nabeshima Y. The discovery of alpha-Klotho and FGF23 unveiled new insight into calcium and phosphate homeostasis. Cell Mol Life Sci 2008; 65: 3218-3230.

57 Tsuruoka S, Nishiki K, loka T, Ando H, Saito Y, Kurabayashi M et al. Defect in parathyroid-hormone-induced luminal calcium absorption in connecting tubules of Klotho mice. Nephrol Dial Transplant 2006; 21: 2762-2767.

58 Brown EM, MacLeod RJ. Extracellular calcium sensing and extracellular calcium signaling. Physiol Rev 2001; 81: 239-297.

59 Brenza HL, Kimmel-Jehan C, Jehan F, Shinki T, Wakino S, Anazawa H et al. Parathyroid hormone activation of the 25-hydroxyvitamin D3-1alphahydroxylase gene promoter. Proc Natl Acad Sci USA 1998; 95: 1387-1391.

60 Kim E, Barrett SMB, Boitano Scott, Heddwen Brooks. Hormonal control of calcium and phosphate metabolism and the physiology of bone. In: Lange/McGraw-Hill (ed). Ganong's Review of Medical Physiology. McGraw-Hill Medical: New York, NY, USA, 2010, pp 363-375.

61 Hoenderop JG, van Leeuwen JP, van der Eerden BC, Kersten FF, van der Kemp AW, Merillat AM et al. Renal Ca2+ wasting, hyperabsorption, and reduced bone thickness in mice lacking TRPV5. J Clin Invest 2003; 112: 1906-1914.

62 Christakos S, Ajibade DV, Dhawan P, Fechner AJ, Mady LJ. Vitamin D: metabolism. Endocrinol Metab Clin North Am 2010; 39: 243-253, table of contents.

63 Kurosu H, Ogawa Y, Miyoshi M, Yamamoto M, Nandi A, Rosenblatt KP et al. Regulation of fibroblast growth factor-23 signaling by klotho. J Biol Chem 2006; 281: 6120-6123.

64 Shimada T, Kakitani M, Yamazaki Y, Hasegawa H, Takeuchi Y, Fujita T et al. Targeted ablation of Fgf23 demonstrates an essential physiological role of FGF23 in phosphate and vitamin D metabolism. J Clin Invest 2004; 113: 561-568.

65 Sitara D, Razzaque MS, Hesse M, Yoganathan S, Taguchi T, Erben RG et al. Homozygous ablation of fibroblast growth factor-23 results in hyperphosphatemia and impaired skeletogenesis, and reverses hypophosphatemia in Phex-deficient mice. Matrix Biol 2004; 23: 421-432.

66 Tsujikawa H, Kurotaki Y, Fujimori T, Fukuda K, Nabeshima Y. Klotho, a gene related to a syndrome resembling human premature aging, functions in a negative regulatory circuit of vitamin D endocrine system. Mol Endocrinol 2003; 17: 2393-2403.

67 Yamashita T, Nifuji A, Furuya K, Nabeshima Y, Noda M. Elongation of the epiphyseal trabecular bone in transgenic mice carrying a klotho gene locus mutation that leads to a syndrome resembling aging. $J$ Endocrinol 1998; 159: 1-8. 
68 Yamashita T, Yoshitake H, Tsuji K, Kawaguchi N, Nabeshima Y, Noda M. Retardation in bone resorption after bone marrow ablation in klotho mutant mice. Endocrinology 2000; 141: 438-445.

69 Kashimada K, Yamashita T, Tsuji K, Nifuji A, Mizutani S, Nabeshima Y et al. Defects in growth and bone metabolism in klotho mutant mice are resistant to $\mathrm{GH}$ treatment. J Endocrinol 2002; 174: 403-410.

70 Teitelbaum SL. Postmenopausal osteoporosis, T cells, and immune dysfunction. Proc Natl Acad Sci USA 2004; 101: 16711-16712.

71 Almeida M, Han L, Ambrogini E, Bartell SM, Manolagas SC. Oxidative stress stimulates apoptosis and activates NF-kappaB in osteoblastic cells via a PKCbeta/ p66shc signaling cascade: counter regulation by estrogens or androgens. Mol Endocrinol 2010; 24: 2030-2037.

72 Liu F, Wu S, Ren H, Gu J. Klotho suppresses RIG-I-mediated senescenceassociated inflammation. Nat Cell Biol 2011; 13: 254-262.

73 Li SA, Watanabe M, Yamada H, Nagai A, Kinuta M, Takei K. Immunohistochemical localization of Klotho protein in brain, kidney, and reproductive organs of mice. Cell Struct Funct 2004; 29: 91-99.

74 Hu MC, Shi M, Zhang J, Pastor J, Nakatani T, Lanske B et al. Klotho: a novel phosphaturic substance acting as an autocrine enzyme in the renal proximal tubule. FASEB J 2010; 24: 3438-3450.

75 Farrow EG, Davis SI, Summers LJ, White KE. Initial FGF23-mediated signaling occurs in the distal convoluted tubule. J Am Soc Nephrol 2009; 20: 955-960.

76 Hu MC, Shi M, Zhang J, Quinones H, Kuro-o M, Moe OW. Klotho deficiency is an early biomarker of renal ischemia-reperfusion injury and its replacement is protective. Kidney Int 2010; 78: 1240-1251.

77 Aizawa H, Saito Y, Nakamura T, Inoue M, Imanari T, Ohyama $Y$ et al. Downregulation of the Klotho gene in the kidney under sustained circulatory stress in rats. Biochem Biophys Res Commun 1998; 249: 865-871.

78 Haruna Y, Kashihara N, Satoh M, Tomita N, Namikoshi T, Sasaki T et al. Amelioration of progressive renal injury by genetic manipulation of Klotho gene. Proc Natl Acad Sci USA 2007; 104: 2331-2336.

79 Zhao Y, Banerjee S, Dey N, LeJeune WS, Sarkar PS, Brobey R et al. Klotho depletion contributes to increased inflammation in kidney of the $\mathrm{db} / \mathrm{db}$ mouse model of diabetes via RelA (serine)536 phosphorylation. Diabetes 2011; 60: 1907-1916.

80 Sugiura H, Yoshida T, Mitobe M, Yoshida S, Shiohira S, Nitta K et al. Klotho reduces apoptosis in experimental ischaemic acute kidney injury via HSP-70. Nephrol Dial Transplant 2010; 25: 60-68.

81 Albaaj F, Hutchison A. Hyperphosphataemia in renal failure: causes, consequences and current management. Drugs 2003; 63: 577-596.

82 Parfitt AM. Renal bone disease: a new conceptual framework for the interpretation of bone histomorphometry. Curr Opin Nephrol Hypertens 2003; 12: 387-403.

83 Shroff RC, Donald AE, Hiorns MP, Watson A, Feather S, Milford D et al. Mineral metabolism and vascular damage in children on dialysis. J Am Soc Nephrol 2007; 18: $2996-3003$

84 de Francisco AM, Ellis HA, Owen JP, Cassidy MJ, Farndon JR, Ward MK et al. Parathyroidectomy in chronic renal failure. Q J Med 1985; 55: 289-315.

85 Milliner DS, Zinsmeister AR, Lieberman E, Landing B. Soft tissue calcification in pediatric patients with end-stage renal disease. Kidney Int 1990; 38: 931-936.

86 Mizobuchi M, Towler D, Slatopolsky E. Vascular calcification: the killer of patients with chronic kidney disease. J Am Soc Nephrol 2009; 20: 1453-1464.

87 Go AS, Chertow GM, Fan D, McCulloch CE, Hsu CY. Chronic kidney disease and the risks of death, cardiovascular events, and hospitalization. N Engl J Med 2004; 351: 1296-1305.

88 Sarnak MJ, Levey AS, Schoolwerth AC, Coresh J, Culleton B, Hamm LL et al. Kidney disease as a risk factor for development of cardiovascular disease: a statement from the American Heart Association Councils on Kidney in Cardiovascular Disease, High Blood Pressure Research, Clinical Cardiology, and Epidemiology and Prevention. Circulation. Circulation 2003; 108: 2154-2169.

89 Levin NW, Hoenich NA. Consequences of hyperphosphatemia and elevated levels of the calcium-phosphorus product in dialysis patients. Curr Opin Nephrol Hypertens 2001; 10: 563-568.

90 Salusky IB, Goodman WG. Managing phosphate retention: is a change necessary? Nephrol Dial Transplant 2000; 15: 1738-1742.
91 Mitani H, Ishizaka N, Aizawa T, Ohno M, Usui S, Suzuki T et al. In vivo klotho gene transfer ameliorates angiotensin II-induced renal damage. Hypertension 2002; 39: 838-843.

92 Kawaguchi H, Manabe N, Miyaura C, Chikuda H, Nakamura K, Kuro-o M. Independent impairment of osteoblast and osteoclast differentiation in klotho mouse exhibiting low-turnover osteopenia. J Clin Invest 1999; 104: 229-237.

93 Hercz G, Pei Y, Greenwood C, Manuel A, Saiphoo C, Goodman WG et al. Aplastic osteodystrophy without aluminum: the role of "suppressed" parathyroid function. Kidney Int 1993; 44: 860-866.

94 Hruska KA, Teitelbaum SL. Renal osteodystrophy. N Engl J Med 1995; 333: $166-174$.

95 Koh N, Fujimori T, Nishiguchi S, Tamori A, Shiomi S, Nakatani T et al. Severely reduced production of klotho in human chronic renal failure kidney. Biochem Biophys Res Commun 2001; 280: 1015-1020.

96 Lee J, Jeong DJ, Kim J, Lee S, Park JH, Chang B et al. The anti-aging gene KLOTHO is a novel target for epigenetic silencing in human cervical carcinoma. Mol Cancer 2010; 9: 109.

97 Pan J, Zhong J, Gan LH, Chen SJ, Jin HC, Wang X et al. Klotho, an anti-senescence related gene, is frequently inactivated through promoter hypermethylation in colorectal cancer. Tumour Biol 2011; 32: 729-735.

98 Wang L, Wang $X$, Jie P, Lu H, Zhang S, Lin X et al. Klotho is silenced through promoter hypermethylation in gastric cancer. Am J Cancer Res 2011; 1: 111-119.

99 Chen B, Wang X, Zhao W, Wu J. Klotho inhibits growth and promotes apoptosis in human lung cancer cell line A549. J Exp Clin Cancer Res 2010; 29: 99.

100 Wolf I, Laitman Y, Rubinek T, Abramovitz L, Novikov I, Beeri R et al. Functional variant of KLOTHO: a breast cancer risk modifier among BRCA1 mutation carriers of Ashkenazi origin. Oncogene 2010; 29: 26-33.

101 Abramovitz L, Rubinek T, Ligumsky H, Bose S, Barshack I, Avivi C et al. KL1 internal repeat mediates klotho tumor suppressor activities and inhibits bFGF and IGF-I signaling in pancreatic cancer. Clin Cancer Res 2011; 17: 4254-4266.

102 Esteller M. Epigenetics in cancer. N Engl J Med 2008; 358: 1148-1159.

103 Perez-Plasencia C, Duenas-Gonzalez A, Alatorre-Tavera B. Second hit in cervical carcinogenesis process: involvement of wnt/beta catenin pathway. Int Arch Med 2008; 1: 10.

104 Semba RD, Cappola AR, Sun K, Bandinelli S, Dalal M, Crasto C et al. Plasma klotho and mortality risk in older community-dwelling adults. J Gerontol A Biol Sci Med Sci 2011; 66: 794-800.

105 Scheiner-Bobis $\mathrm{G}$. The sodium pump. Its molecular properties and mechanics of ion transport. Eur J Biochem 2002; 269: 2424-2433.

106 Anamizu Y, Kawaguchi H, Seichi A, Yamaguchi S, Kawakami E, Kanda N et al. Klotho insufficiency causes decrease of ribosomal RNA gene transcription activity, cytoplasmic RNA and rough ER in the spinal anterior horn cells. Acta Neuropathol 2005; 109: 457-466.

107 Mattson MP. Apoptosis in neurodegenerative disorders. Nat Rev Mol Cell Biol 2000; 1: 120-129.

108 Szydlowska K, Tymianski M. Calcium, ischemia and excitotoxicity. Cell Calcium 2010; 47: 122-129.

109 Li H, Wang B, Wang Z, Guo Q, Tabuchi K, Hammer RE et al. Soluble amyloid precursor protein (APP) regulates transthyretin and Klotho gene expression without rescuing the essential function of APP. Proc Natl Acad Sci USA 2010; 107: 17362-17367.

110 Taguchi A, Wartschow LM, White MF. Brain IRS2 signaling coordinates life span and nutrient homeostasis. Science 2007; 317: 369-372

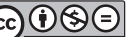

This work is licensed under a Creative Commons AttributionNonCommercial-NoDerivs 4.0 International License. The images or other third party material in this article are included in the article's Creative Commons license, unless indicated otherwise in the credit line; if the material is not included under the Creative Commons license, users will need to obtain permission from the license holder to reproduce the material. To view a copy of this license, visit http:// creativecommons.org/licenses/by-nc-nd/4.0/

(c) The Author(s) 2016 